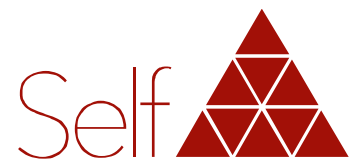

Revista do Instituto Junguiano de São Paulo

\title{
O curador ferido: xamanismo e psicologia analítica
}

\author{
Rejane Maria Gomes Leite Natel \\ São Paulo, SP, Brasil.
}

\section{Resumo}

Auxiliar uma pessoa que se encontra na condição de sofrimento é tentar, a partir de sua história, ajudá-la a dar um sentido a sua vida. Ao estudarmos outras culturas e seus mitos, estamos enriquecendo as possibilidades de nos aproximarmos de nosso paciente, ajudando-o assim a encontrar e a acolher - mito que regerá sua própria vida. A figura do xamã apresenta correspondência no mito do curador ferido em várias mitologias. Sua figura nas sociedades é a do sacerdote, médico, conselheiro e mantenedor das tradições da cultura do grupo. Mas o xamã deve passar primeiro por um processo iniciático, uma jornada heroica, antes que possa se tornar um curador. A função religiosa se manifesta nos processos iniciáticos e define quem está apto a ser representante: ela surge da necessidade da compreensão dos símbolos e de seus significados, originários dos conteúdos universais do homem. Na formação junguiana, a busca por ser um analista se dá na necessária junção da teoria e da vivência analítica, sendo preciso que $O$ analista se submeta a vivências e experiências que propiciem 0 contato com os conteúdos do inconsciente coletivo, por meio de técnicas de análise dos sonhos, imaginação ativa, produção artística e outras. Por meio da relação da psique inconsciente profunda com a consciência, os mitos fundantes são reatualizados, permitindo ao candidato a analista resgatar sua

Conflito de interesses: A autora declara não haver nenhum interesse profissional ou pessoal que possa gerar conflito de interesses em relação a este manuscrito. individualidade na busca por ajudar os outros a fazer o mesmo.

\section{Descritores}

Self, individuação, xamanismo, psicologia junguiana, consciência, inconsciente. 


\title{
The wounded healer: shamanism and analytical psychology
}

\begin{abstract}
To help a person who is suffering is to try, from his history, to help him give meaning to his live. As we study other cultures and their myths, we are enriching the possibilities of getting close to our patient, helping him to find and to accept the myth that will govern his own life. The figure of the shaman is related to the myth of the wounded healer in various mythologies. In societies his figures corresponds to priest, physician, counselor and maintainer of the traditions of the group's culture. But the shaman must first go through an initiatory process, a heroic journey, before he can become a healer. The religious function is manifested in the initiatory processes and defines who is capable of being a representative: it arises from the need to understand symbols and their meanings, from the human universal contents. In the Jungian formation, the search to be an analyst takes place in the necessary junction of theory and analytic experience, and the analyst needs to submit himself to experiences that provide contact with the contents of the collective unconscious through techniques of dream analysis, active imagination, artistic production and others. Through the relationship of the deep unconscious psyche with the consciousness, the founding myths are updated, allowing the candidate to be an analyst who redeems his individuality in the search to help others to do the same.
\end{abstract}

\section{Descriptors}

Self, individuation, shamanism, Junguian psychology, conscience, unconscious. 


\section{El sanador herido: el chamanismo y la psicología analítica}

\section{Resumen}

Ayudar a una persona que está en una condición de sufrimiento es intentar, a partir de su historia, ayudarla a dar sentido a su vida. Al estudiar otras culturas y sus mitos, estamos enriqueciendo las posibilidades de acercarnos a nuestro paciente, ayudándole así a encontrar y a aceptar el mito que gobierna su propia vida. La figura del chamán corresponde al curador herido en varias mitologías. Su figura en las sociedades es la del sacerdote, médico, consejero y encargado de mantener las tradiciones culturales del grupo. Pero el chamán debe pasar primero por un proceso de iniciación, un viaje heroico, antes de que pueda convertirse en un sanador. La función religiosa se manifiesta en el proceso de iniciación y define quien es capaz de ser el representante: ella surge de la necesidad de entender los símbolos y sus significados, del contenido universal humano. En el entrenamiento de Jung, la búsqueda de ser analista se da en la combinación necesaria de la teoría y de la experiencia analítica, lo que requiere del analista someterse a las experiencias que proporcionan el contacto con el contenido inconsciente colectivo a través de técnicas de análisis de sueño, imaginación activa, producción artística y otras. A través de la relación de la psique inconsciente profunda con la conciencia, los mitos fundadores han sido representados, lo que le permite al candidato a analista rescatar su individualidad en la búsqueda de ayudar a los demás a hacer lo mismo.

\section{Descriptores}

Self, individuación, chamanismo, psicología junguiana, conciencia, inconciente. 


\section{Somos pessoas em busca de cura}

[...] não precisamos correr sozinhos o risco da aventura, pois os heróis de todos os tempos a enfrentaram antes de nós. $\bigcirc$ labirinto é conhecido em toda a sua extensão. Temos apenas que seguir a trilha do herói, e lá, onde temíamos encontrar o abominável, encontraremos um Deus. E lá onde esperávamos matar alguém, mataremos a nós mesmos. Onde imaginávamos viajar para longe, iremos ter o centro da nossa própria existência. E lá, onde pensávamos estar sós, estaremos na companhia do mundo todo. (Campbell \& Moyers, 1990, p. 131)

Nossa vida, dia após dia, ultrapassa em muito os limites de nossa experiência consciente e, sem que o saibamos, a vida do inconsciente acompanha a nossa existência. Apesar de ser única, cada pessoa é também um sujeito coletivo em suas representações e manifestações religiosas. Estas representações simbólicas contam as histórias dos povos e dos seus deuses.

Ernest Cassirer (1994) observa que "Não há nenhum fenômeno natural, e nenhum fenômeno da vida humana, que não seja passível de uma interpretação mítica, e que não peça uma interpretação." (p. 123)

A religião pode ser definida como o universo simbólico de um grupo de pessoas, uma comunidade, representado por um mito fundante e outros mitos e ritos que organizam e estabelecem as normas de conduta da comunidade. $\bigcirc$ que entendo por religião é o contato com o si-mesmo ou Self, o arquétipo da orientação e do significado.

\section{O xamã como curador ferido}

mito do curador ferido é o fundamento das sociedades xamânicas. Seu mitologema central traz o homem ferido (meio-homem-meio-deus) que, superando sua dor e sofrimento, ao curar-se, passa a poder curar a dor da humanidade.

Curador ou xamã geralmente é um eleito e é identificado em seu grupo por apresentar, desde a infância, características que o diferenciam dos demais membros. Para as sociedades xamânicas, o homem e a natureza são o "todo" integrado em um pensamento de identidade. Como sacerdote das sociedades tribais, o xamã é um intermediário entre o sagrado e o profano. Frequentemente é também o conselheiro e intermediário nos conflitos da comunidade.

xamã usa técnicas de êxtase, por meio de rituais e drogas alucinógenas, como forma de entrar em contato com os ancestrais e as divindades, ou seja, os arquétipos do inconsciente coletivo, especialmente o arquétipo do simesmo existente no nosso inconsciente mais profundo. 


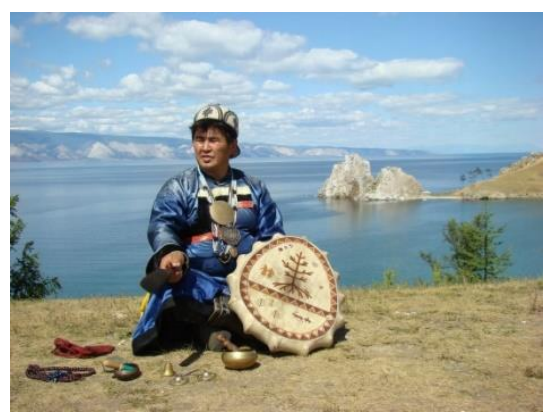

Figura 1. Xamã de Olkhon, Valentin Hagdaev, Olkhon (Baikal). Reproduzido de Wikimedia Commons, https://commons.wikimedia.org/wiki/File\%3AKhagdaev1.JPG. Atribuição: Аркадий Зарубин at ru.wikipedia [CC BY-SA 3.0 (http://creativecommons.org/licenses/by-sa/3.0)], via Wikimedia Commons.

Segundo Mircea Eliade (1998),

Todo medicine-man cura, mas o xamã emprega um método que The é exclusivo. As técnicas xamânicas de êxtase, por sua vez, não esgotam todas as variedades da experiência extática registrada na história das religiões e na etnologia religiosa; não se pode, portanto, considerar qualquer extático como um xamã; este é um especialista em transe, durante o qual se acredita que sua alma deixa o corpo para realizar ascensões celestes ou descensos infernais. (p. 16)

Nas sociedades xamânicas esse processo extático de possessão é induzido e controlado por técnicas rituais.

Segundo I. M. Lewis (1977),

A possessão é tomada tanto como involuntária (ou incontrolada) e voluntária (controlada). Os que praticam a possessão controlada, "dominando" os espíritos são conhecidos no contexto ártico como "xamãs". Retenho este termo para homens e mulheres que exerçam uma ampla gama de funções sociais nessa base. A obtenção do chamado xamanístico é normalmente o clímax de uma série de experiências traumáticas e "curas" no decorrer das quais a extensão de seu controle sobre o transe aumenta progressivamente. Ele acaba por adquirir uma relação estável. (p. 76)

A vocação do xamã é um chamado dos deuses ou dos espíritos para que ele se torne um curador, geralmente associado a uma experiência extática que modifica sua vida e que pode se dar a conhecer em situações de extremo perigo físico e psíquico: visões, sonhos premonitórios, perdas, lutos, doenças iniciáticas graves e outros sofrimentos. 


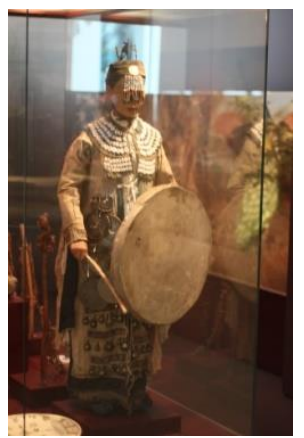

Figura 2. Xamã mulher do povo Oroqen, minoria étnica chinesa. Reproduzido de Wikimedia Commons, https://commons.wikimedia.org/wiki/File:Schamanin_der_Mergen-Oroqen_03.JPG. Atribuição: By Bin im Garten (Own work (own picture)) [CC BY-SA 3.0 (http://creativecommons.org/licenses/by-sa/3.0)], via Wikimedia Commons.

Segundo Marie-Louise von Franz (2004),

[...] a vocação continua a encerrar o significado original da palavra: um chamado dos deuses ou dos espíritos para que ele se torne curador. Os xamãs (bem como muito dos curandeiros e curandeiras de outros povos) passam por período específico de treinamento e desenvolvimento. São chamados por espíritos do clã ou por outros espíritos, frequentemente contra a vontade deles. (p. 299)

Muitas sociedades xamânicas acreditam na hereditariedade do chamado. A linhagem é respeitada em muitas dessas sociedades, e os velhos xamãs transmitem as tradições e os conhecimentos religiosos e de cura apenas a seus descendentes. Essa vem a ser a origem do mito do primeiro xamã.

Conteúdos afetivos de grande carga emocional colocam o xamã em contato direto com os espíritos. Ele é o único capaz de se comunicar com eles, de ouvi-los e encaminhá-los ao mundo dos mortos.

\section{O processo iniciático do xamã}

Xamãs passam por processos de iniciação que geralmente incluem testes de resistência física, psíquica e espiritual, em uma forma de jornada heroica. Ao resistir e enfrentar todo o processo iniciático de treinamento e aprendizado, geralmente transmitido de forma oral, o candidato a xamã está apto a ser o curandeiro do grupo. 


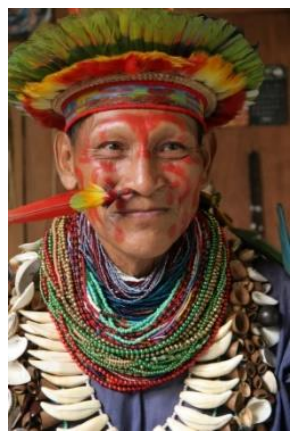

Figura 3. Xamã da Amazônia Equatoriana. Reproduzido de Wikimedia Commons,

https://commons.wikimedia.org/wiki/File:Chaman_amazonie_5_06.jpg. Atribuição: By Veton PICQ (Own work) [GFDL (http://www.gnu.org/copyleft/fdl.html), CC-BY-SA-3.0 (http://creativecommons.org/licenses/by-sa/3.0/) or CC BY-SA 2.5-2.0-1.0 (http://creativecommons.org/licenses/by-sa/2.5-2.0-1.0)], via Wikimedia Commons.

von Franz (2004) lembra que:

Antes que o xamã se apresente, a alma da pessoa destinada a essa função é tomada por espíritos e arrastada para o mundo subterrâneo ou o mundo superior. As almas dos futuros xamãs são então colocadas em ninhos de diferentes níveis nos galhos de uma árvore, sendo geralmente incubadas e criadas por uma mãe do reino animal sob a forma de um corvo ou outro pássaro, ou por um alce ou veado alado etc. Essa mãe do reino animal é o alterego do xamã, seu duplo, seu espírito protetor e seu princípio vital. Às vezes ele devora o xamã e o dá a luz novamente, ou então, o choca enquanto ele está no ovo. Além disso, a iniciação xamanística geralmente também consiste, como sabemos, na mutilação do candidato e na sua redução a esqueleto. Este último apresenta a substância básica imperecível a partir da qual o xamã renovado pode ser reconstituído. Nem sempre o novo xamã está no controle de sua nova forma; às vezes, ele a encontra apenas nos momentos cruciais, durante a iniciação ou na hora da morte, mas é através desse alterego interior que ele realiza suas curas. (p. 299)

von Franz (2004) afirma ainda que "É estritamente proibido agir como xamã enquanto o período da iniciação não termina e o iniciado não está curado da sua doença iniciatória." (p. 301)

Ao atingir a condição de xamã, ele passa então a ser o mantenedor das tradições da tribo, e suas funções incluem ser o depositário da cosmovisão do grupo, partindo de seus mitos de criação; reter o conhecimento das técnicas de êxtase, que the permitem alcançar estados alterados de consciência e assim entrar em contato com os espíritos; e promover a cura simbólica de forma a devolver ao doente sua integridade física, psíquica e espiritual. 


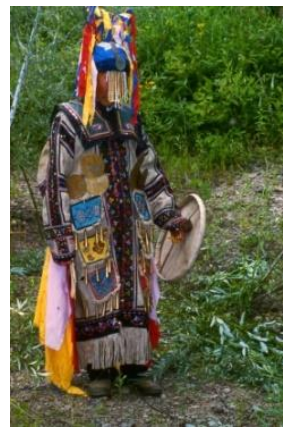

Figura 4. Chuonnasuan (1927-2000), o ultimo xamã do povo Oroqen, na China. Foto de julho de 1994, por Richard Noll. O xaanismo desse povo da Manchúria está extinto. Reproduzido de Wikimedia Commons, https://commons.wikimedia.org/wiki/File:Chuonnasuan, the_last_shaman_of_the_Oroqen,_in_July_1994_(Photo_b y_Richard_Noll).jpg. Atribuição: By Richard Noll at English Wikipedia [Public domain], via Wikimedia Commons.

Mas mesmo depois de aceito, o xamã ainda dependerá de sua capacidade de curar e de transmitir as tradições religiosas da sua cultura para obter o respeito e reconhecimento do grupo.

Mircea Eliade (1998) define a figura do xamã como o mito vivo, contido na vida cotidiana da sua cultura.

\section{Universo simbólico do xamã}

O universo simbólico xamanista inclui sua indumentária, ervas, objetos - tais como tambor e maracás (termo brasileiro para um chocalho específico), animais de poder e outros: estes são a representação da integração de sua natureza física e espiritual e também de sua linhagem e de sua comunidade.

Segundo Mircea Eliade (1998),

A indumentária xamânica constitui em si mesma uma hierofania e uma cosmografia religiosa: revela não apenas uma presença sagrada, mas também símbolos cósmicos e itinerários metafísicos. Examinando com atenção, a indumentária revela o sistema do xamanismo com a mesma transparência que os mitos e técnicas xamânicas. (p. 169)

Eliade (1989) ainda afirma que

A maioria desses cânticos rituais com fim medicinal começa por evocar a cosmogonia: "No início, no tempo em que os céus, o sol, a lua, os astros, os planetas e a terra não tinham ainda aparecido, quando nada tinha ainda aparecido etc." E conta-se a criação do mundo, o nascimento dos demônios, o aparecimento das doenças e finalmente a epifania do xamã primordial [...] que trouxe medicamentos necessários. (p. 30) 


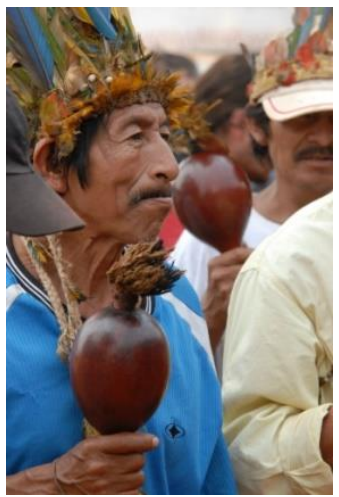

Figura 5. Xamã guarani na dança que marcou a despedida do encontro de lideranças para o lançamento da campanha "Povo Guarani, Grande Povo!", Caarapó (MS), Brasil. Reproduzido de Wikimedia Commons, https://commons.wikimedia.org/wiki/File:Xam\%C3\%A3_guarani.jpg. Atribuição: By Roosewelt Pinheiro/ABr [CC BY $3.0 \mathrm{br}$ (http://creativecommons.org/licenses/by/3.0/br/deed.en)], via Wikimedia Commons.

Nas sociedades xamânicas, a cosmogonia explica o início e a origem da doença e o porquê de sua aparição. A sua ritualização possui um caráter medicinal. A evocação do xamã primordial acontece para que ele possa trazer os medicamentos necessários para a cura. $\bigcirc$ cântico, as ervas, o tambor, a identificação com animais protetores, as danças e os diversos objetos são utilizados ritualisticamente para a obtenção da cura. Estes objetos representam as forças e os instrumentos necessários para lidar com os perigos que o xamã enfrentará em sua busca por acalmar os espíritos perturbadores que causaram a doença ao indivíduo.

Marie-Louise von Franz (2004) nos lembra que:

Os símbolos do espírito animal-mãe, do tambor, da árvore e de muitos outros, em tão grande número que é impossível descrevêlos todos, são, sob o aspecto da psicologia junguiana, símbolos do Si-mesmo. Na tradição xamanística, o futuro curador não apenas precisa ter sofrido uma invasão do inconsciente coletivo, como também ter chegado ao seu núcleo, ao que Jung chamava de Si-mesmo. Estranhamente, com frequência o Si-mesmo primeiro confronta a pessoa de maneira hostil, como algo explosivo que poderia até provocar a loucura. (p. 300)

\section{O processo de formação do psicoterapeuta junguiano}

A proposta da psicoterapia junguiana traz representações simbólicas que podemos observar também no xamanismo - não querendo dizer com isso que sejam processos idênticos, mas sim que existem paralelismos e analogias sob uma perspectiva simbólica. Segundo Jung e von Franz, para ser um psicoterapeuta junguiano, o candidato necessita, no contato com o inconsciente profundo e seus fenômenos numinosos, passar por processos muito semelhantes aos processos iniciáticos de um xamã. $\bigcirc$ treinamento e a 
vocação exigidos para $\bigcirc$ xamã podem servir como orientação para os futuros analistas junguianos. Acompanhar o paciente no mergulho em seus símbolos e por meio dos sonhos e de outras técnicas - tais como imaginação ativa e expressão artística - é ajudá-lo a buscar em si mesmo aquilo que está contido em seu centro e totalidade psíquicas: o Self.

Esses autores alertam que o psicoterapeuta, para além do aprendizado teórico, do treinamento e da vocação, necessita passar por um longo processo de autoconhecimento, submetendo-se ele mesmo às provas de resistência que o processo analítico impõe na busca da cura simbólica, sob o risco de permanecer com seus pacientes em um nível superficial de terapia, eventualmente fazendo mais o papel de orientador do que o de curador.

Segundo Marie-Louise von Franz (2004),

A partir do ponto de vista da psicologia profunda atual, essa experiência xamanística importa em sofrer uma invasão do inconsciente coletivo e ter êxito ao lidar com ela. Quando a análise de treinamento do futuro analista permanece presa à discussão de problemas pessoais, de acordo com minha experiência, essa pessoa nunca se torna, mais tarde um analista eficaz. Somente quando experimenta o infinito na sua vida, como Jung formulou, é que a vida encontra significado. Caso contrário, ela se perde em superficialidades. (pp. 299-300)

Exige-se do futuro analista grande conhecimento. Mas o simples conhecimento teórico que se pode obter não permitirá, sozinho, auxiliar o paciente. A capacidade de curar o outro exige do curador poder reconhecer e acolher a dor do outro e a possibilidade de curar a si mesmo. Esta cura pode acontecer àquele que, na busca por individuação, consegue enfrentar seu inconsciente profundo e depois retornar a sua vida consciente e cotidiana transformado por suas crenças e seu universo simbólico.

A cura simbólica se dá nos âmbitos espiritual e psicológico.

Para Donald Sandner (1997)

[...] o cerne de todos os métodos culturais e psicológicos de cura que ocorram em sociedades letradas ou iletradas é uma estrutura simbólica que explique ou, pelo menos, ofereça um contexto de significação para o sofrimento de seus membros. Há muito o que tolerar: a exaustiva monotonia da vida diária, o apocalíptico aparecimento de enfermidades e tragédias, e o sofrido resultado da ignorância e da maldade humana. Dentro da estrutura simbólica de sua cultura, o homem tenta criar um sentido satisfatório para esses sofrimentos e um método para curá-lo. (p. 25)

A vocação do analista para estar a serviço do outro tem que ser o ponto central da sua escolha e pode também ser considerada como um chamado, pois a necessidade de entrar em contato com o próprio inconsciente exige 
do mesmo a submissão da consciência ao si-mesmo e à função religiosa nele contida.

mito do curador ferido se sobrepõe e delineia os propósitos do Self em uma trajetória de sucessivos enfrentamentos com o mundo interior. Ao nos depararmos com o nosso próprio sofrimento e com nossas dúvidas, vivenciando-os no processo simbólico, podemos nos identificar e nos aproximar do nosso próprio mito, do nosso próprio curador ferido e assim compreender com tolerância e valorização os mitos de outras culturas e sociedades.

Para von Franz (2004)

Tudo o que dissemos aqui sobre o xamanismo dos povos circumpolares se aplica, de maneira surpreendente, à problemática vocacional dos terapeutas atuais. A pessoa que não tenha tido acesso às profundezas do inconsciente, e visto ali "a natureza de todos os espíritos da doença", dificilmente pode possuir uma empatia real e suficiente com relação ao grave sofrimento psíquico dos seus semelhantes. Ela só os tratará de acordo com as regras, sem jamais ser capaz de sentir empatia por eles, e este é frequentemente o fator-chave para os pacientes. (p. 301)

A vocação para o ofício - simultaneamente um ser escolhido e escolher torna-se então profissão, ofício, lugar no mundo. Este ofício vem carregado de uma carga afetiva, que só identificamos, muitas vezes, ao longo da vida. É comum vermos adultos, que na infância sofreram doenças graves, ao se curarem, se transformarem em grandes médicos, grandes curadores. E assim o mito do curador ferido se mantém vivo em nosso inconsciente.

\section{Cura científica e cura simbólica}

Discrimino a cura em dois universos distintos para melhor compreender como ela se dá em nossa sociedade contemporânea: a cura simbólica e a cura científica.

A cura científica da nossa sociedade laica moderna é objetiva e racional em seu aparato tecnológico, bioquímico e instrumental, e pressupõe que um tratamento qualquer, cientificamente testado, funcionará de maneira previsível em qualquer pessoa ou grupo de pessoas independentemente de sua cultura e das suas crenças. Essa é a conceitualização que nossa sociedade contemporânea parece ter da cura.

Já o xamanismo, assim como a maioria das religiões e mitologias, se diferencia por propiciar a cura simbólica.

Para Edward F. Edinger (1993), "[...] ergue-se no horizonte um novo modo, a saber, a psicologia profunda. A nova dispensação psicológica descobre a relação do homem com Deus na relação do indivíduo com o inconsciente." (p. 86) 
Também entendo a psicologia analítica como capaz de promover uma cura simbólica, o que a diferencia de outras abordagens dentro da ciência: "a psicologia, de algum modo, é quem faz a comunicação entre esses dois modos de ver a cura." (Natel, 2003, p. 72)

Segundo Aldo Natale Terrin (1998),

A visão xamânica implica também uma definição e uma concepção de saúde que se diferenciam de maneira clara da visão ocidental. A saúde é um fato "total", é um bem-estar, um "estar bem" do corpo e do espírito, num justo equilíbrio entre as forças da natureza e as forças espirituais e esse equilíbrio pode ser unicamente o resultado de uma manutenção da relação estreita com os âmbitos internos da realidade: antes de tudo, o espírito que se deve harmonizar com o corpo, com o mundo circunstante, com a natureza, com o mundo senciente, com os outros e com o mundo dos espíritos. (p. 229)

\section{O xamã demoníaco e o analista arrogante}

Mas como podemos avaliar a eficiência da cura? Evidentemente ela se dará no restabelecimento da saúde do paciente, seu bem-estar e seu retorno à vida cotidiana.

Para o xamanismo essa cura se dá quando o sujeito não está à mercê de espíritos perturbadores, feitiços ou da perda de pedaços da alma em momentos de extremo sofrimento, traumas e lutos. $O$ xamã é o mediador entre o mundo dos vivos e dos mortos; é ele quem entra em contato com o mundo dos mortos e obtém os conhecimentos e instrumentos para ajudar seu paciente a se curar.

Também o papel do analista junguiano deve ser o de um facilitador no processo de individuação de seu paciente, ao possibilitar a comunicação entre dois mundos: o mundo da consciência e o mundo do inconsciente.

No contexto psicológico, a cura só é efetiva quando a individuação ocorre, melhor dizendo, quando a pessoa solidifica sua personalidade natural e passa a exercê-la, deixando de estar à mercê da agitação de afetos internos, de projeções ou simplesmente dos modismos de sua sociedade.

Tanto no xamanismo, quanto na psicologia de abordagem junguiana, devemos ter cuidado extremo ao falarmos em cura, especialmente ao levarmos em conta a possibilidade de emergência de um curador demoníaco.

Segundo Marie-Louise von Franz (2004),

No contexto etnológico, contudo, o curador também tem uma sombra específica, ou seja, essa vocação também possui um contraaspecto sombrio. Trata-se da figura do xamã ou curandeiro 
demoníaco. A forma mais superficial disso é o terapeuta que é governado por um complexo de poder. É evidente que nessa profissão, na qual o indivíduo é seu próprio senhor e amo, e na qual as outras pessoas frequentemente se agarram a ele de maneira ingênua e infantil, o abuso do poder representa uma enorme tentação. Por exemplo, o analista pode se ver tentando assumir o papel do pai ou do sábio, aquele que sabe o que está certo. Por mais repugnante que isso seja, não é, na minha opinião, o mais perigoso, visto que esses terapeutas são de modo geral devidamente importunados por pacientes igualmente possuídos pelo poder, ou punidos, através do fato de que eles tendem a reunir ao redor de si um tedioso jardim-de-infância de pacientes que os atormentam com exigências. (p. 303)

Quando o paciente não se permite atender ao chamado do seu próprio mundo interior, estabelece-se uma resistência que mantém a pessoa fixada no mundo externo de forma literal. Essa atitude gera uma neurose que afasta artificialmente a pessoa da dor por meio de um mecanismo defensivo que, como consequência funesta, o impedirá de viver situações criativas na vida diária.

curador demoníaco causará outros quadros neuróticos e tomará como cura novas doenças da alma, exercendo sob seus pacientes poder e controle que, ao invés de buscar realmente pela cura, manterá o paciente em dependência com novos conflitos e eterna servidão ao curador.

O curador demoníaco é chamado de xamã negro ou sanguinário porque pratica magia negra: escolhe a feitiçaria e atua com ela. A arrogância dos xamãs frequentemente é vista como verdadeira fonte do mal.

von Franz afirma (2004)

- curador demoníaco é algo em escala maior, algo mais perigoso. Os Yakuts, por exemplo, acreditam que no momento da iniciação, o xamã tem a escolha de ser iniciado pelos espíritos da "fonte da destruição e da morte" ou pelos "espíritos da cura e da salvação". [...] A partir do ponto de vista psicológico, os xamãs do mal são aqueles que encontraram o acesso ao inconsciente e se mostraram suficientemente fortes para não serem derrubados por ele, mas que, por assim dizer, intencionalmente se rendem aos impulsos sombrios do inconsciente. (p. 303)

E conclui: "Na minha opinião, essa arrogância também existe entre os terapeutas modernos, e os que são marcados por ela são, creio eu, mais perigosos do que aqueles com treinamento profissional inadequado." (von Franz, 2004, p. 304)

Podemos observar esse fenômeno em certos profissionais que se tornam verdadeiros gurus em nossa sociedade, eventualmente provocando 
fanatismos e perda de consciência crítica em seus pacientes e na sociedade em geral.

Em algumas religiões contemporâneas, discursos emocionais de líderes manipuladores podem eventualmente produzir episódios de histeria coletiva, despersonalizando os indivíduos possuídos pela "participation mystique".

Jung mais de uma vez fez alusão a Hitler como um exemplo de salvador negativo ou destruidor e, de fato, foram imensos o sofrimento e a vergonha que o nazismo causou à humanidade como um todo.

Segundo Jung (2002), “[...] a magia negra exalta os impulsos destrutivos como única verdade válida em oposição à ordem até agora existente e, além disso, compele a servir ao indivíduo em oposição à coletividade." (p. 256)

\section{Considerações finais}

Ao entrarmos em contato com o nosso Self, corremos o risco de encontrarmos uma posição transcendente, uma terceira via, diferente das duas que invariavelmente constituem o par de opostos do conflito psíquico: retornamos da jornada conscientes de conteúdos profundos e permitimos a transformação dos valores da consciência de modo a estarem de acordo com o si-mesmo, integrando-os então na nossa vida cotidiana. Trazer à luz da consciência aquilo que em nós permanece na escuridão da nossa psique ancestral - e compreender o conceito de saúde como integração psíquica entre consciência e inconsciente - é a possibilidade de dar sentido à existência. Na direção contrária, nos afastamos de nós mesmos.

A tomada de consciência é algo que só pode ser feito pelo indivíduo.

Tratar a religiosidade humana como mero pensamento mágico, sem valor no contexto sociocultural da modernidade, é função do domínio do pensamento científico na cultura contemporânea que, transformado em visão de mundo, desmerece o caráter religioso e simbólico da própria cultura e do ser humano.

A humanidade, ao longo da sua história e desenvolvimento, apresenta um imenso conteúdo de símbolos e mitos. O xamanismo - assim como o animismo e todas as formas de religiões posteriores - é um conjunto diverso de simbologias e mitologemas. Os mitos habitam nosso inconsciente coletivo como motivos básicos de formações de ideias que herdamos de nossos antepassados; emergem da nossa história de vida e são definidores na relação com a sociedade na qual estamos inseridos. $\bigcirc$ inconsciente coletivo é a nossa herança individual deixada por toda a humanidade em seu processo de desenvolvimento. Em função da evolução da diversidade cultural, esses símbolos foram sendo transformados e ressignificados, mas, ao nos depararmos com os momentos críticos de nossas vidas, o sentido e a carga afetiva do acontecimento primordial, que foi introjetado em nosso inconciente, retornam. Nesse processo que é a própria vida, enfrentamos 
situações de extremo sofrimento, tais como perdas, lutos, conflitos e doenças, as quais, muitas vezes, nos remetem a um vazio existencial, geram distúrbios e desajustamentos tanto no meio em que convivemos quanto em relação a nós mesmos.

Jung pergunta (1986):

Quem é este Deus? Esta pergunta se impôs à humanidade em todas as partes do mundo e em todos os tempos e sempre de novo, de forma semelhante: uma força do além, a que estamos abandonados, que cria assim como mata, uma imagem das necessidades e dos fatos inevitáveis da vida. Como, do ponto de vista psicológico, a figura de Deus é um complexo de ideias de natureza arquetípica, deve ser considerada como representante de uma certa soma de energia (libido), que aparece de forma projetada. Nas principais religiões da atualidade os atributos de Deus parecem ser derivados da imago paterna, em religiões mais antigas também da imago materna. São eles o poder dominador, o pai atemorizante e rancoroso (Antigo Testamento), e o pai amoroso (Novo Testamento). Em certas imagens pagãs o lado materno sobressai muito, acrescentando-se ainda o elemento animal, o teriomorfo. (pp. 48-49; OC V: 89)

A vida se torna insípida e sem criatividade se nos afastamos do contato com aquilo que naturalmente somos, incluindo o que desconhecemos em nós mesmos: ela fica plena de neuroses que nós mesmos construímos, com comportamentos, máscaras e racionalizações que cristalizam o nosso viver.

O inconsciente coletivo é um sucessivo acúmulo de experiências e vivências, que em cada um de nós expressa sentidos e simbologias de origens comuns, porém, com revestimentos diversos: o afastamento da vida simbólica nos despersonaliza e nos afasta do centro organizador da vida psíquica que é o si-mesmo.

Para Jung (1986):

A figura religiosa não pode ser apenas um homem; ela deve representar aquilo que realmente é, a totalidade daqueles protótipos que sempre e em todos os tempos exprimem o "extraordinariamente eficiente". Sob a forma humana visível não se procura o homem, mas o super-homem, herói ou o deus, justamente o ser semelhante ao homem, que exprime aquelas ideias, formas e forças que comovem e moldam a alma humana. Para a experiência psicológica são os conteúdos arquetípicos do inconsciente (coletivo), aqueles resíduos da remota humanidade comuns a todos os homens, aquele patrimônio geral sobrevivente a toda diferenciação e desenvolvimento, que é dado a todos os homens como a luz do Sol e como o ar. Mas ao amarem este legado, amam aquilo que é comum a todos; voltam assim à mãe da humanidade, à psique que era antes de existir um consciente, 
e readquirem desse modo uma parcela desta coesão e desta força secreta e irresistível que emana da sensação de solidariedade com o todo. (p. 163; OC V: 259)

Como analistas, devemos ter a capacidade de acolher nosso próprio processo de autoconhecimento e individuação, para podermos almejar ajudar nossos pacientes a fazerem o mesmo. Para isso, é necessário conhecer e exercitar tantos as funções psicológicas superiores quanto as inferiores.

A função religiosa nos remeterá ao nosso centro psíquico e, ao nos encontramos com a imagem de Deus, estaremos em confronto com episódios e experiências numinosas que trarão à nossa consciência a possibilidade de autoconhecimento, permitindo assim nos identificarmos com um universo simbólico que nos auxiliará no objetivo de estar a serviço do outro.

A aproximação do xamanismo e da psicologia analítica se dá, simultaneamente, no nível do inconsciente coletivo, onde os símbolos nos remetem aos primórdios da humanidade, e no nível da consciência, tanto individual quanto coletiva, aos nos identificarmos com esses símbolos e darmos importância a eles e a sua universalidade. Desse modo, poderemos continuar, mulheres e homens, pessoas contemporâneas, a lhes dar significado.

Só podemos oferecer ao outro aquilo que possuímos. Nossas características inatas, nossa história de vida e o lugar que ocupamos no mundo nos obrigam a viver mitos que revelam o nosso processo de individuação.

\section{Referências}

Campbell, J. \& Moyers, B. (1990). O poder do mito. São Paulo: Palas Athena.

Cassirer, E. (1994). Ensaio sobre o homem. São Paulo: Martins Fontes.

Edinger, E. F. (1993). A criação da consciência. São Paulo: Cultrix

Eliade, M. (1989). Aspectos do mito. Lisboa (Portugal): Edições 70.

Eliade, M. (1998). O xamanismo e as técnicas arcaicas de êxtase. São Paulo: Martins Fontes.

Jung C. G. (1986). Símbolos da transformação. In C. G. Jung, Obras Completas. (volume V). Petrópolis: Ed. Vozes Ltda.

Jung C. G. (2002). Cartas de C.G. Jung, Volume II - 1946-1955. Petrópolis: Editora Vozes.

Lewis, I. M. (1977), Exxtase religioso. São Paulo: Editora Perspectiva. 
Natel, R. M. G. L. (2003). Xamã: símbolo da cura espiritual, a partir de Mircea Eliade. Dissertação de Mestrado, Pontifícia Universidade Católica, São Paulo.

Sandner, D. (1997). Os navajos e o processo simbólico da cura. São Paulo: Summus Editorial.

Terrin, A. N. (1998). O sagrado off limits: a experiência religiosa e suas expressões. São Paulo: Loyola.

von Franz, Marie-Louise. (2004): Psicoterapia. São Paulo: Paulus.

Minicurrículo: Rejane Maria Gomes Leite Natel - Psicóloga. Membro didata do Instituto Junguiano de São Paulo (IJUSP) e da Associação Junguiana do Brasil (ABJ). Professora convidada no Centro Universitário Salesiano de São Paulo (Unisal). Mestre em Ciências das Religiões pela Pontifícia Universidade Católica de São Paulo (PUC/SP); especialista em Psicologia Junguiana. Diretora Administrativa do IJUSP (2016/2018).E-mail: rrn@uol.com.br 